Thilo Weber

\title{
The Proform/Conjunction Interface: A Study of the Syntax of Relative That
}

\section{Introduction and Survey of Previous Studies}

"'THAT' is evidently regarded by many writers as nothing more than an ornamental variation for 'who' and 'which', to be used, not indeed immoderately, but quite without discrimination. The opinion is excusable; it is not easy to draw any distinction that is at all consistently supported by usage" (Fowler:1908).

This paper is concerned with the syntactic status of the English word that in sentences such as I read the book that you gave me, He knew the woman that came to him, and I'll tell you the reason that I went home. In descriptions of the word, relative that has long been treated in two ways: One group of scholars has classified it as a subordinating conjunction or complementiser ${ }^{1}$, standing outside the functional structure of its clause and merely serving as a marker of subordination. According

1 For a discussion of terminology see section 3. 
to that view, relative that is the same lexical item as the word that in sentences such as I know that you are right, where it serves to introduce a complement clause. On the other hand, that has been analysed as a pronoun basically comparable to the $w h$-pronouns. The latter view is the traditional analysis, to be found for example in Sweet (1898:80) and Wendt (1911:213). In the 1920s, the traditional view was first challenged, most prominently by Otto Jespersen, who in his 1927 work A Moderm English grammar on historical principles argued that it seemed best "not to call the relative that [...] a pronoun at all", but a "conjunction" (1927:165). Most transformationalists have followed Jespersen's line of thought and regarded the complementiser and the relative marker the same word. In the transformational approaches by Klima (1964), Stahlke (1976), Dekeyser (1988), and Radford $(1988 ; 2006)$, relative that is considered identical with the complementiser. Nontransformationalists, too, have shared that view. In his diachronic study, Smith (1982:78-81) agrees with Jespersen's proposal that the word originated as a pronoun but is now a complementiser. The complementiser analysis is also present in descriptive grammar: Huddleston and Pullum (2002:1056) consider that a conjunction. So does Miller $(1988 ; 1993)$ in his grammar of Scots.

Nonetheless, the complementiser analysis has not eliminated the traditional pronoun analysis. In the descriptive grammar by Quirk, Greenbaum, Leech and Svartvik (henceforth Quirk et al.) that is treated as a relative pronoun (1985:366). Seppänen and Kjellmer (1995:396), Trotta and Seppänen (1998), and most explicitly Seppänen $(1993 ; 2000)$ reject the complementiser analysis in favour of the pronoun analysis. Kim and Sells (2008), too, treat that as a relative pronoun in their very recent introduction to English syntax mainly based on the feature structure system of Head-Driven Phrase Structure Grammar.

Between the complementiser and the pronoun analysis, various in-between positions have emerged. Zandvoort considers that a "relative particle", being "intermediate between a relative pronoun and a conjunction" (1957:163). Van der Auwera argues that relative that is "not fully pronominal, but highly pronominal" (1985:171).

In addition, more recent transformationalists, such as Pesetsky (1982:306) and Haegeman (1991:424-425; 1999,193-194) have to some extent reviewed the analysis that relative that and complementiser that are identical and adjusted it to "the intuition that the element that $[. .$.$] is not quite the ordinary complementizer but$ that it also acts like a relative pronoun" (Haegeman 1991:424). And while Stahlke promotes the complementiser analysis in his 1976 paper "which that", he reconsiders his position in a contribution to an internet forum in 1991: "I think there is much less stability in the use of "that" and "wh-" relatives than most published 
studies would suggest. That "that" would be used pronominally in relatives is not surprising, given its history."2

In this paper I will compare those various positions and review their validity. After giving a brief summary of the formation of bound relative clauses within government and binding theory, I will define the terms conjunction, including the subcategories of subordinator and complementiser, and contrast them with the terms relative word/wh-word, and with term relative particle. Subsequently, I will turn to the properties of relative that in present-day English and investigate its syntactic status in comparison to words from the categories previously examined.

I will argue that relative that is a wh-operator and thus not the same word as the complement-clause introducing conjunction that. I will show that its distribution is nearly identical to that of other wh-operators. In several respects, that differs from who, whom, whose, what, and which. That fact, however, will be shown not be detrimental to a wh-analysis of relative that because the undisputed wh-operators themselves differ considerably from one another with regard to characteristics that have been considered to discriminate that from $w h$.

\section{Formation of Bound Relative Clauses within Govern- ment and Binding Theory}

Within the framework of GB, the formation of bound relative clauses is a process that involves deletion of the relativised constituent, insertion of a $w h$-constituent, and movement from its logical D-structure position into clause-initial position, where it appears in S-structure. The movement is known as wh-movement, but has also been called $w h$-topicalisation or $w h$-fronting. The moved constituent is considered to leave a "gap" or "trace" in its original position. The following illustration is primarily based on Haegeman's Introduction to Government and Binding Theory (1991).

2 Stahlke, Herbert. "Message 3: That's." The LINGUIST LIST, 16 September 1991, http://list serv.linguistlist.org/cgi-bin/wa?A2=ind $9109 \mathrm{c} \& \mathrm{~L}=$ linguist\& $\mathrm{P}=524$, accessed on 29 January 2008. 
(1) the man whom Lord Emsworth will invite

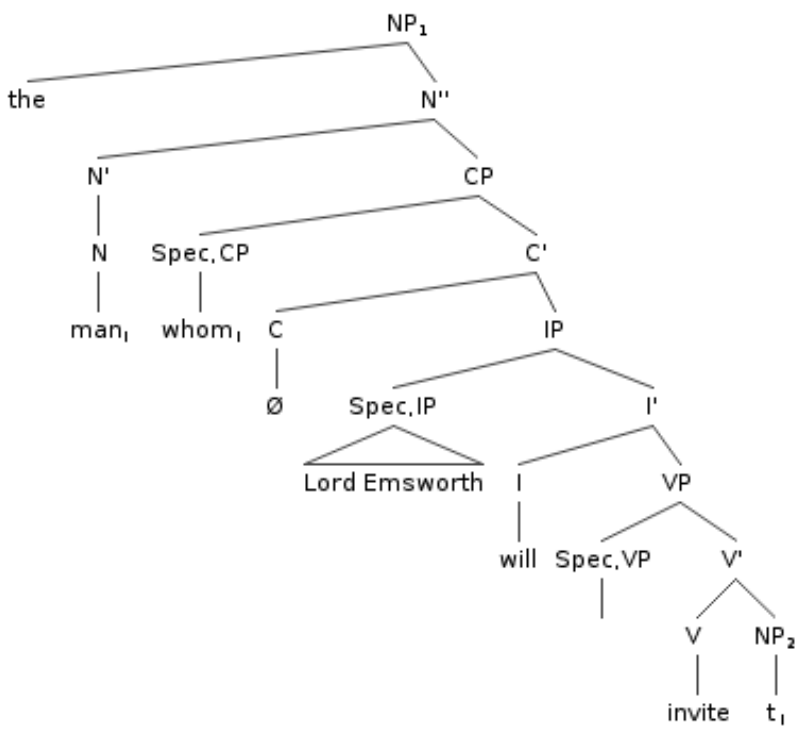

The example shows the most frequent type of relative clause: The CP functions as a sentential modifier within an NP. It is controversial what syntactic constituent makes up the antecedent, i.e., the element that is modified by the clause. ${ }^{3}$ For example, it is disputed whether it is a noun or an NP. For Haegeman, the antecedent in (1) consists of the "head noun man" (1991:370). The antecedent is coreferential with an element in the relative clause, which is called the relativised element. In (1), that element is in the position of the internal argument of invite, i.e. in direct object position. The coreferentiality is indicated by the index $i$. The relativised element in the clause is substituted with a $w h$-constituent and by means of wh-movement, it is moved from the direct object position into a position to the left of the IP, leaving a coreferential trace $t$ in its original postverbal position. Since the $w h$-constituent is regarded a maximal projection, of the two positions $\mathrm{C}^{0}$ and $[\mathrm{SpecCP}]$ to the left of the IP it can only be moved into [SpecCP] because $\mathrm{C}^{0}$ is reserved for heads. The head of the CP is an element from the closed class of complementisers, one of which is that. Although wh-operators and complemen-

3 For Haegeman, the antecedent consists of a head noun (1991:370). Others have suggested that the antecedent consists of the entire NP or the NP excluding the determiner. See Hermann (2003:17) for a survey of different analyses. Baker (1995:334-335) proposes that the antecedents of restrictive relative clauses are nouns and the antecedents of nonrestrictives are NPs. The question of what makes up the antecedent is further complicated if the NP contains a prepositional attribute (e.g. of-genitives) or an AP. Hermann (2003:12) says that what constitutes the antecedent depends on the individual case. Both semantics (e.g. restrictiveness) and morphosyntactic properties (e.g. number congruence between the antecedent and the finite verb) help to identify the antecedent. 
tisers thus do not compete for the same syntactic position, their co-occurrence in English is ungrammatical due to a language-specific constraint. In relative clauses such as (1), which contain an overt wh-operator in [SpecCP], $\mathrm{C}^{0}$ cannot be occupied by an overt complementiser. (2) is ungrammatical in modern Standard English:

(2) *the man whom that Lord Emsworth will invite

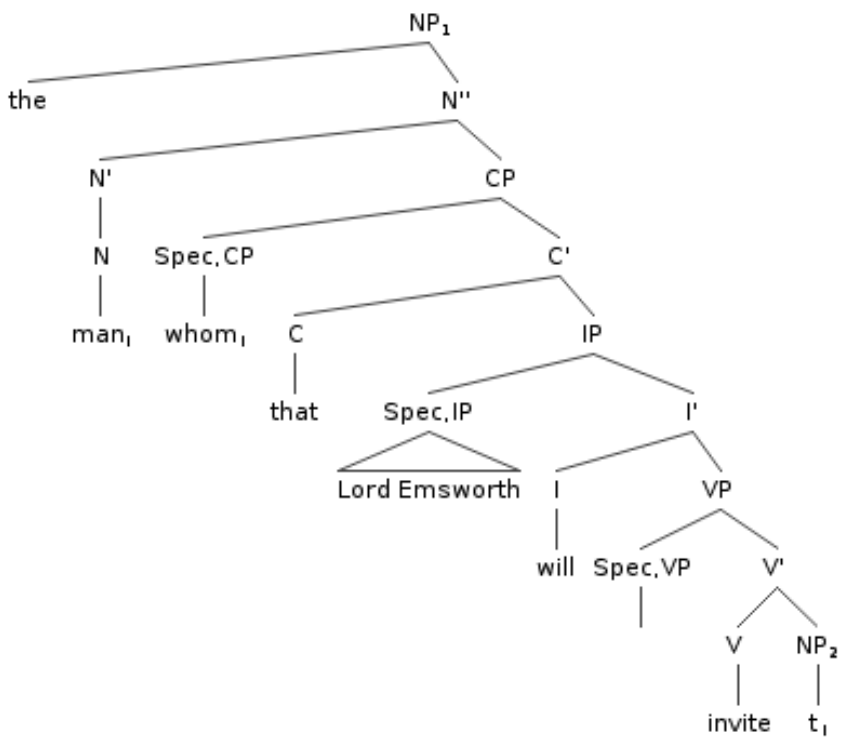

This phenomenon has been captured with the Doubly Filled COMP Filter first formulated by Chomsky and Lasnik (1977) and taken up by Haegeman (1991). It states that "when an overt wh-phrase occupies the Spec of some CP the head of that CP must not dominate an overt complementiser" (Haegeman 1991:349).

As the formulation "overt $w h$-phrase" suggests, apart from overt $w h$-phrases, Haegeman also assumes the existence of a non-overt $w h$-phrase, an "empty operator" (1991:422). Radford (1988:485) proposes the same, using the term "empty wh-operator". Apart from being invisible, this empty operator behaves like its overt counterparts. It is coreferential with its antecedent, moves into [SpecCP], and leaves a coindexed trace. Since the Doubly Filled COMP Filter applies to overt wh-operators only, the non-overt operator can co-occur with an overt complementiser. The sequence of the empty wh-operator, represented by the symbol $O$ in [SpecCP], followed by the overt complementiser that in $\mathrm{C}^{0}$ is Haegeman's and Radford's analysis of the that-relative, i.e. the construction being the topic of this paper: 
(3) the man that Lord Emsworth will invite

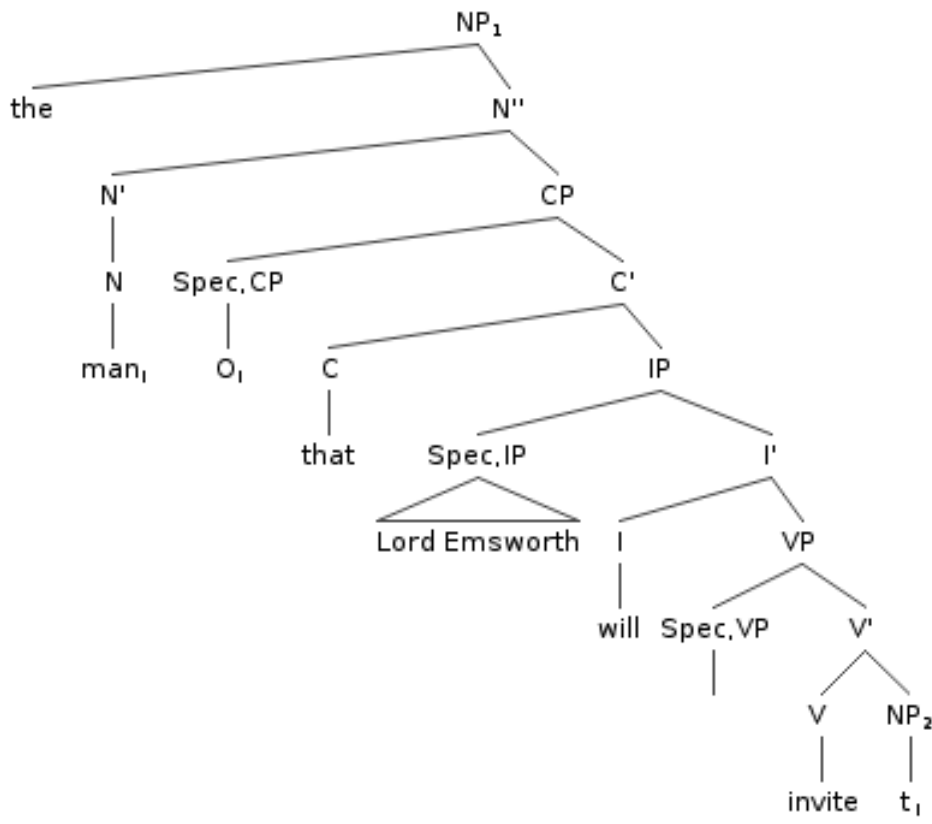

According to Radford (1988:491) and Haegeman (1991:423), contact-relatives involve an empty wh-operator as well as an empty complementiser, with complementiser-omission being "a possibility generally available in English" (Haegeman 1991:423). This is illustrated in (4):

(4) the man i O i Ø Lord Emsworth will invite t i

In sum then, relative clauses within GB theory are derived from an underlying structure that corresponds to that of a declarative clause. The relativised constituent is deleted, replaced with a wh-operator and moved into clause-initial position to the left of the complementiser-position. That is believed not to be one of those $w h$-operators but to be a complementiser. However, according to Haegeman and Radford, that relatives as well as contact relatives, too, begin with a wh-operator, namely with a non-overt one. 


\section{The Syntax of Clauses Introduced by Conjunctions, Relative Words, and Relative Particles}

In this section, I will deal with the various labels that have been introduced to refer to relative that. First I will define the terms conjunction, subordinating conjunction/subordinator, and complementiser, which have appeared in the conjunction analysis. In a next step, I will contrast those terms with the terms wh-word/relative word and wh-pronoun/relative pronoun, which have been used in the pronoun analysis. Lastly, I will consider the term relative particle and contrast it with the other terms. In the first subsection I will investigate their syntactic status within their own clause. In the second subsection I will compare the external syntax of clauses introduced by conjunctions, relative words, and particles.

\subsection{Internal Syntax: The Status of the Word within its Clause}

\subsubsection{Conjunction}

Within the category of conjunction, the big division is that between coordinating conjunctions and subordinating conjunctions, which are also known as subordinators. Coordinate conjunctions link two elements that are syntactically the same without making one of them dependent on the other. The elements conjoined need not be clauses but may also be phrases or only parts of phrases. By contrast, subordinators always link clauses:

(5) She was early although she had missed the bus.

The subordinator marks the clause it introduces as subordinate and incorporates it into a matrix clause. That always introduces subordinate clauses so that if it a conjunction, it can only be a subordinator.

The term complementiser is ambiguous. As Van der Auwera (1985:163) argues, there are at least three different ways of using the term complementiser. According to him, the term was first introduced by Rosenbaum (1967) in order to distinguish the subordinator that from other subordinators, such as although in (5). In his original definition, a complementiser is a subordinator that serves to introduce complement clauses only, as illustrated in the examples in (6):

(6) a I know that the world is flat.

b The idea that the world is flat proves to be correct 
In Rosenbaum's usage, the term complementiser does not apply to that when it is used to introduce relative clauses. There are crucial differences between complement clauses and relative clauses: A complement clause does not contain a relativised element. Neither is there an overt wh-operator, nor are there a covert $w h-$ operator and a gap. Moreover, complement clauses, as the name suggests, take the syntactic position of complements. In (6a), the clause is the obligatory complement of the verb know. In (6b) the clause is the complement of the noun idea. Noun complement clauses are restricted to a small number of nouns, such as idea, which C-select for a sentential complement, whereas relative clauses are modifiers and can modify innumerable most heterogeneous nouns such as cat, energy, health, boy etc. (Huddleston and Pullum 2002:1039). Van der Auwera adopts Rosenbaum's narrow meaning of complementiser defined as the type of subordinator that introduces complement clauses.

Rosenbaum's definition of complementiser was widened considerably by Bresnan (1970). She argues that every clause has a complementiser node. A complementiser may now introduce subordinate clauses other than complement clauses and, as main clauses, too, have a complementiser node, a complementiser does not even need to be a subordinator (van der Auwera 1985:163-164). Haegeman (1991:111-112), too, considers every clause to be headed by a complementiser node. That way, not only complement clauses, but also relative clauses may be introduced by a complementiser, as shown above.

Between the narrow Rosenbaum/Van der Auwera definition and the broad Bresnan definition, there is an in-between position with complementiser being used as a synonym to subordinator. Stahlke does not restrict the term to elements that introduce complement clauses, but he does restrict it to elements introducing embedded clauses. Similarly, for Smith the term complementiser refers to "morphemes marking subordinate clauses" (1982:35).4 In the same way, Miller calls that both a "complementiser" (1988:118) and a "conjunction: in relative clauses, but also in complement clauses" (1993:113). That means he uses the term in the same way as Stahlke and Smith do.

\subsubsection{Relative Word}

A subordinator or a complementiser in the usage last mentioned is an element that marks a clause as subordinate and incorporates it into a matrix clause. In that respect, it does not differ from those elements that are generally referred to as wh-

4 Smith's usage of the terms, however, is confusing. He says that complementiser and subordinator are alternative terms for morphemes marking clauses as subordinate. He chooses not to use the term subordinator because he says that it is important to distinguish between types of subordinate clauses, such as complement clauses and relative clauses. But then he uses the term complementiser to refer to that in complement clauses and in relative clauses alike. Thereby he neutralises the distinction, cf. Smith (1982:36-37). 
words or relative words. However, apart from those shared properties, there are crucial differences between the two types of elements. Within transformational grammar, the terms wh-word or relative word refer to words that replace the relativised constituent in the relative clause and undergo $w h$-movement. They may either be moved as a phrase in their own right, or they may be part of a larger phrase, which is called a "relative phrase" (Trotta and Seppänen 1998:352; Huddleston and Pullum 2002:1039). (7a-b) are examples of simple relative phrases; (7c-d) show complex ones. The relative phrase is in italics, the relative word is in bold type. The examples are taken from Trotta and Seppänen (1998:352):

(7) a I couldn't identify the player who $t$ incurred the penalty

b He was born in London, where he also spent most of his life $t$

c He really loved that old song, the name of which I can't recall $t$ right now

d She won't wake up till around three o'clock, by which time I'll be in Phoenix $t$

Huddleston and Pullum present six types of upward perlocation forming complex relative phrases out of a relative word and other material (2002:1039). By contrast, conjunctions do not constitute a phrase within their clause, nor can they enter into a complex phrase within their clause.

The sentences in (7) illustrate a number of other characteristics distinguishing relative words and conjunctions. Although relative words are often found in clause-initial position, they do not necessarily have to be the first word of their clause. As it is the relative phrase that introduces the clause rather than the individual relative word, "the relative word is in absolute initial position necessarily only if it is co-extensive with the RelP, but need not be the first word in a complex RelP" (Trotta and Seppänen 1998:353). This can be seen in (7c-d). By contrast, conjunctions have to be in clause-initial position.

In D-structure the relative phrase occupies a position within the functional structure of the IP and is $w h$-moved into clause-initial position. In S-structure, the relative phrase retains its functional role, which is indicated by a coreferential trace left in the logical D-structure position. In (7a) the relative phrase is in subject position, in $(7 c)$ it is the direct object, and in $(7 b+d)$ it is in adverbial function. Apart from the trace in the original position, nominal relative phrases may also indicate their functional role by means of case-marking. In (7a), the relative phrase who is in subject position and is thus in nominative case. In sharp contrast to this, subordinators occupy a position outside the functional structure of their own clause without having been moved there from a position inside the functional structure (ibid: 353). In (5), the entire subordinate clause may function as an adverbial within the matrix clause, but the conjunction itself stands outside the functional 
structure of its own clause. Of course, that also applies to the complementiser that in (6).

Semantically, too, the relative phrase has a role within its own clause. It has referential quality and identifies a participant $(7 \mathrm{a}+\mathrm{c})$ or a circumstantial element, such as place (7b) or time (7c), involved in the action or process described (Trotta and Seppänen 1998:355).

Huddleston and Pullum (2002:1039) observe that when an antecedent is modified by a relative clause, there are two coreferential pairs of different extents: Firstly, the gap in the original position of the relative phrase is coreferential with the moved relative phrase. E.g. in $(7 \mathrm{c})$, the entire italicised relative phrase the name of which is coreferential with the gap/trace $t$. Secondly, the relative word within the relative phrase is tied to its antecedent by a relationship of coreferentiality. E.g. in $(7 \mathrm{c})$, which is coreferential with its antecedent song. When the relative word and the relative phrase are coextensive, as in $(7 a+b)$ and the following examples in (8), no such distinction between the two coreferential pairs is necessary. Coreferentiality often causes the relative word to show semantic concord with its antecedent (Trotta and Seppänen 1998:354; 2000:36; Radford 1988:483). This accounts for the patterns of grammaticality and ungrammaticality in (8):

(8) a The man i who i / *which i went home

b The book i which i / *who i I am interested

c The reason i why i / * where i I went home

d The place i where i $/ *$ why i I had a cup of coffee

$(8 \mathrm{a}+\mathrm{b})$ shows that relative pronouns show animacy concord with their antecedent. The contrast between who for animate nouns and which for inanimate ones is an example of semantic agreement. The examples in $(8 c+d)$ show that semantic concord is a feature also shared by relative adverbs. Trotta and Seppänen argue that subordinating conjunctions are not referential items (1998:354). Consequently, they cannot be coreferential with any other element and are thus not subject to semantic concord. By contrast, Smith analyses relative that as a complementiser that "retains the deictic aspect of OE demonstrative pat because it refers to an antecedent" (1982:154). Thus, referential quality is a disputed criterion to distinguish relative words and conjunctions.

What is more, the sentences in (7) show that the relative word may take different positions within its relative phrase, which indicates a general difference between conjunctions and relative words: "'Subordinator' is a term for a word-class, whereas 'relative' does not name a class of words but a certain set of syntactic (and semantic) properties that are not tied to any particular word-class but cut right across several such classes", as Trotta and Seppänen observe (1998:353). In English, there are relative pronouns, as in $(7 \mathrm{a}+\mathrm{c})$, relative adverbs, as in $(7 \mathrm{~b})$, and relative determiners, as in $(7 \mathrm{~d})$. Therefore, the terms wh-word/ relative word are not to be 
used as synonyms to the terms wh-pronoun/relative pronoun. A relative pronoun is a certain type of relative word. Huddleston and Pullum use the term "proform" to refer to the group of words that Seppänen and Trotta consider to share the set of properties that make them relative (2002:1056).

Morphological invariance is not considered criterial to identify a complementiser in contrast to a relative word. According to Smith, it has been suggested to regard the alternation of that, for, and $\varnothing$ under the $\mathrm{C}^{0}$ node a case of "complementizer allomorphy" or "suppletion". Moreover, he argues that there are cases of inflected complementisers in other languages, such as $a$ and $a r$ in Irish, which alternate according to the tense of the verb in the clause they introduce (1982:10). Since the term relative has been shown to apply to words from various word classes, they should not be expected to show inflectional similarities as the inflectional properties depend on the respective word class. However, individual types of relative words may be identified by looking at their inflection. E.g., inflection for case and gender/animacy is a typical characteristic of English pronouns but not of complementisers and can thus help to distinguish a relative pronoun from a complementiser.

\subsubsection{Relative Particle}

The terms particle and relative particle are the most controversial ones and the ones creating the most definitional confusion. Smith disapproves of the term saying that "to call a word a 'particle' is to indicate that it is a member of a minor category; little else is revealed" (1982:36). The term relative particle is commonly understood to refer to an element intermediate between a relative word, in particular a relative pronoun, and a conjunction. That view is advocated by Zandvoort (1957:163). For Van der Auwera, a relative particle is "a non-pronominal, invariant, clause-introductory relativiser. The difference with a conjunction is that the latter simply isn't a relativizer. Otherwise, a conjunction and a relative particle are the same" (1985:158). Using the term relativiser, Van der Auwera does not refer to an element undergoing $w h$-movement as in the transformationalist approaches; the term rather describes a word serving the function of introducing a clause that postmodifies an antecedent, thus referring to the external syntax of the clause. This broader definition of relativiser will be addressed in more detail in the next section.

In Hermann's usage, relative particles are not as similar to conjunctions as they are in van der Auwera's view. She uses the term particle to refer to those relative markers that cannot be governed by a preposition and are indeclinable (ibid: 50; 195). Even though she may use the term relative particle synonymously to the terms conjunction/complementiser (2003:113), she also says that "REL pronouns, REL particles, and the zero marker $\varnothing$ have to surrender their normal (postverbal) clause position in the clause (i.e., the position they would occupy in a 
simple declarative clause) and move to initial position" (ibid: 49-50). Following Hermann, a relative particle thus has a functional role in its clause. She considers relative that a "particle" (ibid: 50), which e.g. may function as "subject" (ibid: 160). Fulfilling a functional role within the clause has overwhelmingly been considered a characteristic of $w h$-words/relative words rather than of conjunctions.

\subsubsection{Summary}

In sum, both subordinators and relative words have been shown to be words that introduce clauses, mark those clauses as subordinate, and incorporate them into a matrix clause. However, while the term subordinator refers to a word class, the term relative word or wh-word refers to a set of properties which are not tied to a specific word class. Words from the word class of subordinator have been shown to lack those properties: While relative words form potentially complex relative phrases, conjunctions do not. The relative phrase is in a fronted position, leaving a gap in its original position that indicates its functional role. By contrast, conjunctions stand outside the functional structure of the clause they introduce. In addition, the relative word and the relative phrase have referential quality whereas conjunctions do not, which, however, has been seen to be a controversial criterion. Morphological variance is not a valid criterion to distinguish relative words and conjunctions.

The term relative particle refers to words which in their function of introducing a clause that postmodifies an antecedent resemble $w h$-words, but which lack at least some of the properties that have been considered criterial to $w h$-words. The label relative has thus been expanded beyond the group of $w h$-words. This broader usage of the term will be presented in the following section.

\subsection{External Syntax: The clause as a Post-Modifier of an Antecedent Head}

So far, the term relative word has generally been used with a narrow definition synonymous to the term wh-word. The terms have been shown to refer to words from across different word classes sharing certain properties. Since words from the category of conjunction lack those properties, the terms relative and conjunction are contrastive.

On the other hand, the term relativisation has been used in another way. Apart from the narrow definition closely associated with $w h$-movement, there is a broad definition with relativisation referring to any clause construction that serves to postmodify an antecedent. Referring to the external syntax of the clause, it is noncommittal to its internal syntax. It does not determine whether $w h$-movement is involved, nor does it determine the category of the word introducing the clause. The terms relative and relativiser in the broad usage subsume conjunctions, whwords, and particles when they serve to introduce a clause that postmodifies an 
antecedent. That definition of the term has already been mentioned briefly in connection with relative particles. Relative particles carry the label relative due to the similarity between the external syntax of clauses introduced by $w h$-words and clauses introduced by relative particles rather than due to any formal similarity between $w h$-words and particles themselves.

Examples of the broad usage of the term can be found throughout the discourse: Stahlke argues that the speaker has the choice between "relativization by copying and deletion, or relativization by that-insertion and deletion" (1976:595). Radford calls relative that a "relative clause complementiser" (2006:146) and consequently speaks of "[c]omplementizer [r]elatives" and "wh-relatives" (1988:490). Smith points out that " $w h$-words and that belong to different categories but have identical functions in relative clauses, i.e. introducing relative clauses" (1982:3536). Therefore, the two "belong to a general category of relative marker, which includes pronouns and complementizers" (ibid: 79-80). Similarly, Van der Auwera uses the term relativiser not only to refer to relative pronouns and relative adverbs (1985:151) but also includes relative particles, which in his view resemble conjunctions: "The difference with a conjunction is that the latter simply isn't a relativiser. Otherwise, a conjunction and a relative particle are the same" (ibid: 158). Thus, what is criterial to a relativiser, once more, is the function of introducing a relative clause.

Since there is no doubt that that is a relativiser in the broad sense of the word, the question I will address in this paper is what type of relativiser that is. I will consider whether it is a relative in the narrow sense of the word, i.e. a wh-word, whether it is a subordinator, or whether neither characterisation is appropriate.

\section{The Syntactic Status of Relative That in Present-day English}

\subsection{Inflection and Agreement}

A major argument to support the thesis that that is not a relative pronoun centres on the inflection of the relative. English relative pronouns can inflect for case, animacy, and number (with collective nouns). Their case is determined by their position within the relative clause while inflection for number and animacy is determined by agreement with their antecedent, to which they are tied by a relationship of coreferentiality.

\subsubsection{Case}

In Standard English, the wh-pronouns who and which have case-marked forms. Who and which have a genitive whose; who has a (formal style) accusative whom. By con- 
trast, that does not have any oblique case forms. Radford argues that the absence of those variant case-forms in standard language supports the thesis that the word is not a pronoun but a complementiser (1988:483; 2006:146).

However, there are a number of arguments that diminish Radford's thesis. Huddleston and Pullum note that a number of speakers "are inclined to think that [whose] is restricted to personal antecedents" (2002:1050). For those speakers, which lacks a synthetic genitive, too. Having no accusative form either, which is morphologically invariant in the usage of those speakers. Besides, whose, when used as a genitive of which, is not a morphological but a suppletive genitive, which opens the possibility for saying that relative that has a suppletive genitive whose, too, as van der Auwera argues (1985:154).

More importantly, what needs to be considered with regard to case-marked relative pronouns is the considerable discrepancy between prescriptive grammar and actual spoken English: Hermann, who analysed relative clauses in traditional English dialects, found out that "[c]ase-marked wh-pronouns (whose; whom) [...] are (still) hardly found in dialectal speech (0.28\% altogether)" (2003:192). Thus, at least in spoken English, that and wh-pronouns in the vast majority of cases do not contrast as far as their case-marking is concerned.

Moreover, the dissimilarity between that and wh is further diminished by the fact that that does have an oblique form in a number of dialects: The following example comes from Seppänen and Kjellmer (1995:394):

(9) The dog that's leg is broken

The genitive that's, according to Seppänen, is well attested from many varieties of English such as Scottish, Irish, American and English, "including even its use in fully standard language" (1993:371):

(10) It delivers a VHS picture the like of which the world has never seen. A picture that's quality of detail, colour and resolution is unrivalled (The Observer)

However, the form that's is controversial. Firstly, its frequency and distribution is disputed: While Seppänen and Kjellmer argue that it "shows signs of spreading in present-day usage" (1995:397), Miller says that at least in Scots "that's no longer occurs" (1988:118).

Secondly, the status of the form as a morphological genitive pronoun is not accepted by all scholars. Huddleston and Pullum state that the form does not "necessitate a pronoun analysis for the dialects concerned" (2002:1057). Miller argues that the form is a coalescence of the complementiser that followed by the

5 See Hermann (2003: 135) for a survey of dialectologists citing that's. 
possessive pronoun his or its (1988:118). A lot of spoken dialects, among them Scots, do not have any wh-pronouns. That way, whose is not available to the speakers and "the place of a boy whose name is taken by a boy that his name or its wakened form a boy that's name" (Seppänen and Kjellmer 1995:397). However, that's is also used where a sequence of that their (11a) or that her (11b) would be appropriate. In addition, Seppänen and Kjellmer found out that that's + noun is also accepted in non-subject position (11c), which shows that there must have been wh-movement: That's cannot be a contraction of that and his because in the uncontracted form, his would follow the verb:

(11) a the people that's houses were demolished (Seppänen and Kjellmer 1995: 391)

b The woman that's sister marriet the postie (Seppänen and Kjellmer 1995: 389)

c The dog that's owner I told [ $t$ to leave is lying over there. (Seppänen and Kjellmer 1995: 394)

The sentences in (11) show that the $s$ is not a clicicised possessive pronoun but that it has been reinterpreted as a genitive marker. That re-interpretation, however, is crucial on the assumption that that is an NP and not a complementiser, since the normal genitive structure is NP's (Seppänen 1993:371). Seppänen proves that a reinterpretation with a complementiser analysis of that is not possible:

(12) a I didn't know that his ( $>$ that's) brother was at home

b I didn't know that their ( $>*$ that's) brother was at home

c I didn't know that her ( $>$ *that's) brother was at home

Seppänen argues that the complex NP containing that's "can only occupy the same Spec-CP position which is the normal landing site of fronted whelements" (Seppänen 2000:47).

That's is a morphological genitive of that and the case-marked form is a strong argument in favour of the pronoun analysis. The only English constituents that inflect for case are NPs. However, the relation between case-marking and (pro)nominal status is not a biconditional one because not all wh-pronouns inflect for case. Therefore, even if one does not accept the oblique form that's, the absence of that form is not sufficient to disprove the pronoun analysis, nor does it favour the complementiser analysis. 


\subsubsection{Agreement}

\subsubsection{Animacy}

English relative pronouns have a two-partite system of gender marking, distinguishing animate/personal and inanimate/nonpersonal antecedents. In Standard English, whose is insensitive to animacy (e.g. Huddleston and Pullum 2002:1050), who/whom is used to refer to animate antecedents, and which is used to denote inanimate ones. That is avoided in favour of who when it functions as an animate subject (Quirk et al 1985: 1250). ${ }^{6}$ Thus, while $w$ b-pronouns and relative that differ with respect to case-marking, they do not contrast with respect to inflection for animacy in standard language.

However, as in the case of case-marking, there is a difference between prescriptive grammar and non-standard language. According to Miller, many spoken varieties of English do not have any $w h$-pronouns so that the relativiser that is used "[r] egardless of whether the relative clause modifies a human or non-human, animate or inanimate noun" (1988:114). Miller and van Gelderen argue that the who/that dichotomy is a result of prescriptive rules and mostly a characteristic of educated English (ibid; van Gelderen 2004:70). Hermann agrees that in traditional English dialects "personal that functioning as subject occurs frequently and freely" (2003:117). Yet, she notes that there is a who/that contrast in spoken American (ibid).

The varying degree of gender-marking which relative that shows in spoken English, however, does not clearly discriminate it from the wh-pronouns. Hermann argues that "which is NOT confined to nonpersonal antecedents in dialects", either (ibid: 122). She cites occurrences of personal which in examples such as the following:

\section{(13) a $[\ldots]$ And the boy which I was at school with $[\ldots]$}

Van der Auwera argues that in earlier stages of English, both relative that and which could freely have animate antecedents and then underwent a process of "dehumanization" (1985: 153), i.e. they started to become sensitive to gender/animacy. ${ }^{7}$ He argues that the dehumanisation of which is completed and that of that is not.

Besides, whose is not consistent with regard to gender-marking, either. It is insensitive to gender in Standard English though for a number of speakers it tends

6 In object position, that is more accepted with personal antecedents because it helps speakers to avoid the choice between the very formal whom and the prescriptively incorrect who (Quirk et al 1985:367).

7 See Smith (1982:66-67) for a survey of the historical development of which and Hermann (2003:118) for a survey of the historical development of that with respect to gender sensitivity. 
to be confined to animate antecedents (Huddleston and Pullum 2002:1050). However, Miller notes that many spoken varieties totally lack whose (1988:118).

Similar to case-marking, gender-marking has been shown not to be a necessary condition for pronominal status. The wh-pronouns which and whose as well as relative that show gender-marking in some varieties whereas they lack gender-marking in other varieties.

By comparison with other relative markers, however, that is the relative marker that can occur most freely with both animate and inanimate antecedents.

\subsubsection{Number}

Stahlke states that relative that, unlike the demonstrative pronoun that, fails to undergo number agreement, which challenges its pronominal status (1976:592). He gives the following example:

(14) *What happened to the books those were on the table?

Stahlke's argument is odd. In (14), neither which nor vernacular what would show number agreement, nor would who in a corresponding structure with an animate antecedent. (14) merely shows that relative that is different from the demonstrative pronoun that. ${ }^{8}$ Smith notes that etymologically those would be an unlikely plural form of relative that anyway (1982:75).

The only case in which English relative pronouns inflect for number is with collective nouns. Levin argues that " $\mathrm{t}]$ here is great consistency in the use of which + singular verb, on the one hand, and who + plural verb on the other. [...] The distribution of verbs with relative pronouns indicates that it is reasonable to treat which as a singular form and who as a plural form when referring to collective nouns" (1999:2). He provides the following examples:

(15) a (..) it was a threat to the government which under $\mathrm{Ne}$ Win has steadfastly fought against his country's ethnic groups.

b So collectors will want some of the figures from the past of their favourite regiments, 'wiped out' by their own Government, who have accomplished what the Chinese army just failed to do in the Korean War.

Relevant to the current discussion is Levin's observation that "that was also used with only singular verbs" (1999:2). Consider (16):

8 It is uncontroversial that relative that is different from the demonstrative pronoun that. The demonstrative can be the complement of a preposition while the relativiser cannot. In addition, the demonstrative is neuter whereas the relativiser can take masculine, feminine and neuter antecedents (van der Auwera 1985: 592). 
(16) The deal is another example of a company that stubs its toe - but has a decent franchise - selling out at what appears to be a reasonable price $(\ldots)$

In her diachronic analysis, van Gelderen argues that relative that is no longer a relative phrase in [SpecCP] but a complementiser head in $\mathrm{C}^{0}$ and is thus generally no longer subject to agreement. Nonetheless, she observes that that sometimes shows reflexes of its ancestor, the Old English relative pronoun pat, which was originally confined to singular antecedents, in that it takes a singular verb even though the antecedent is plural (van Gelderen 2004:76):

(17) There are other things you talked about that is not on the tape

Number agreement is a typical feature that is checked between the finite verb and its subject. It favours the pronoun analysis over the complementiser analysis.

\subsubsection{Summary}

As far as inflection is concerned, there is no clear-cut difference between relative that and $w h$-pronouns. Lack of inflection cannot disprove the analysis of that as a pronoun since typical $w h$-pronouns do not consistently inflect for case, number, and animacy, either. While inflection for those three categories is thus not a necessary condition for pronominal status, it may be considered a sufficient condition to favour the pronoun analysis over the complementiser analysis. However, it is controversial, whether that fulfils that condition. That has a genitive that's, but the form is restricted to certain dialects. Its gender-marking is restricted to Standard English and certain varieties, too. Lastly, that may be assumed to be marked for singular when referring to collective nouns but more data seems to be necessary to decide if that + plural verb is really uncommon.

The examination of the inflection of that has brought to light a lot of geographic variation as well as a significant discrepancy between standard and nonstandard language. In varieties that use that's, the pronoun theory is strongly favoured. In varieties such as Standard English, in which there is no such genitive but where $w h$-pronouns are in use and that suppletively alternates with who to indicate animacy (and number), the pronoun analysis is supported, too. In dialects that do not have a genitive that's and also lack $w h$-pronouns, that is indeclinable so that no positive evidence in support of the pronoun analysis is provided. Nonetheless, as stated above, the absence of morphological variance is not sufficient to disprove the pronoun analysis. 


\subsection{Upward Perlocation}

As presented above, relative proforms form relative phrases. They either constitute a relative phrase in their own right, or they are part of a complex relative phrase. By contrast, conjunctions do not constitute a phrasal constituent or part of a phrasal constituent within their own clause.

In contrast to $w h$-pronouns, relative that cannot enter into a complex phrase. The following examples are taken from Huddleston and Pullum (2002:1057); the relative phrase is in italics:

(18) a the woman whose turn it was

$\mathrm{b} *$ the woman that's turn it was

(19) a the knife with which he cut it

b *the knife with that he cut it

In the section on the inflection of that it has been shown that (18b) does occur in certain varieties. The genitive that's, when it occurs, is always contained within a complex NP. What makes the sentence ungrammatical is thus not the complex NP consisting of that's and turn. It is rather the unacceptability of the oblique form that's itself in Standard English.

(19b), however, seems not to be grammatical in any variety. That cannot be preceded by a preposition. For a number of linguists, that phenomenon is the central argument to support the thesis that that is not a relative pronoun (Jespersen 1927:161; Klima 1964:9; Stahlke 1976:588; Radford 1988: 482; Huddleston and Pullum 2002:1057; Hermann 2003:123-124). While wh-relatives allow both pied-piping and preposition stranding, that can only strand its preposition. Compare (19) and (20):

(20) a the knife which he cut it with

$\mathrm{b}$ the knife that he cut it with

For van Gelderen, the ungrammaticality of (18b) and (19b) indicates that that does not occupy [SpecCP], the landing site for relative phrases after undergoing $w h$ movement, but that it is the head of the CP (2004:70).

Van der Auwera argues that if it is criterial to a relative pronoun that it allows both stranding and pied piping, who and which are not pronominal in infinitival relatives, where only pied piping is allowed (1985:152):

(21) a I found an usher from whom to buy tickets

b *I found an usher whom to buy tickets from 
Miller objects that there is no such contrast simply because he doubts that (21a) really exists: (21a), "if it occurs at all, belongs to a highly formal variety which nobody learns from their parents' spoken language and which is not regularly used even in written English" (1988:116). According to him, infinitival relatives in spoken English do not have any wh-constituent at all: I found an usher to buy tickets from. Miller's sociolinguistic objection diminishes van der Auwera's argument that typical $w h$-pronouns, too, are sometimes confined to one type of preposition placement, as that always is. At the same time, however, data from spoken informal English provides a much stronger argument to alleviate the contrast between that and $w h$-pronouns: In her typological study of relative clause formation in traditional English dialects, Hermann found out that of "38 REL pronouns (i.e., the prepositional complements who, which, and whom taken together), 12 (31.58\%) show preposition fronting while $26(68.42 \%)$ show preposition stranding. In other words, even where preposition fronting is permitted, preposition stranding is preferred in dialectal speech" (2003:124). That means, in $68.42 \%$ of the occurrences of relative $w h$-pronouns, they do not behave differently from that.

Seppänen and Bergh argue that all English relative pronouns, including that, have undergone a syntactic change in their preposition placement since medieval times, first obligatorily fronting their prepositions, then coming to admit stranding as an alternative pattern and then showing stranding as the prevailing structure. They say that the drop in the incidence of stranding in the (written) language of today is due to prescriptive grammar rather than due to genuine grammatical change (200:295). Van Gelderen agrees that there is a historical trend towards preposition stranding, which is counteracted by prescriptive grammar only (2004:70). However, while Seppänen argues that the shifting behaviour towards preposition stranding is a change affecting the morphosyntax of the pronouns but not their status as pronouns (2000:37), van Gelderen assumes that the change in preposition placement does indicate that the $w h$-pronouns are loosing their pronominal status and developing into complementiser heads (2004:70).

However, the change in preposition placement has not changed the fact that who, whose, whom, which, and what refer to nominal constituents. In other words, it does not change their pro-nominal referential quality. Synchronically, too, who and which are no less pronominal with stranded prepositions than they are with pied piped ones.

In treating precedability by a preposition as the defining property of relative pronouns the classification of relative markers becomes counterintuitive. Hermann argues that what, in non-standard language used as a relative marker in bound relatives, is not a pronoun because it cannot follow a preposition (2003:124):

(22) a the book what I talked about

b *the book about what I talked 
Thus, she has to assume a structural difference between (23a) containing a nonpronominal relative marker and $(23 \mathrm{~b})$ containing a pronominal one:

(23) a the book what I talked about

b the book which I talked about

Although what can occur with personal/animate antecedents more freely than which, both elements are overwhelmingly nonpersonal/inanimate (Hermann 2003:112; 115), which means that they show agreement with their antecedent, which has been shown to be a characteristic of pronouns. The vagueness of the argument becomes even more apparent when looking at the behaviour of who: Sag notices that who, too, parallels that in that it cannot be preceded by a preposition (1997:461):

*the people in who/that we placed our trust

Kim and Sells assume that that and who, unlike whom, and which, which can be preceded by a preposition, have no accusative case (2008:234). However, that argument leaves questions unanswered. As far as that is concerned, Seppänen objects that "the lack of formal distinction between the different case forms makes it possible to use the non-distinct forms in certain types of coordinated structures where one occurrence of the form represents the nominative in one clause and the accusative in the other" (2000:45):

(25) At last another date was suggested which/that Gregson said he was not too happy about $[t]$ but all the others felt $[t]$ suited them perfectly

Who, too, can be used as accusative. As long as the preposition that assigns accusative case to the pronoun is stranded, who will be acceptable. Compare (24) and (26):

(26) the people who we placed our trust in

Sag concludes that "the behavior of relative that and relative who appear to be identical. Thus there appears to be little obstacle to the analysis of relative that as a wh-pronoun" (1997:32).

Its inability to follow a preposition marks a clear difference between that and some other $w h$-forms used to relativise NPs. It is a definitional question whether the word cannot be a pronoun for that reason. However, the examination has also shown that pied piped prepositions with wh-pronouns are scarce and that pied piping is historically on the decline, counteracted only by prescriptive grammar. 
Moreover, who and what do not allow preposition fronting, either, without at the same time loosing such pronominal characteristics as referential quality and pronoun antecedent agreement. Therefore, in treating precedability as criterial to pronouns, their status cannot be captured satisfactorily. ${ }^{9}$

\subsection{Wh-Movement and Syntactic Position}

As stated above, within the framework of GB, a relative phrase is considered to occupy the $[\mathrm{SpecCP}]$ position in S-Structure after having undergone $w h$-movement into that position from its logical D-Structure position within the IP. In so doing, the relative phrase leaves a coreferential wh-trace in its original position. By contrast, complementisers occupy the IP-external $\mathrm{C}^{0}$ position without having undergone any movement. In the following I will analyse the behaviour of that with regard to $w h$-movement and its syntactic position.

\subsubsection{Resumptive Pronouns}

A feature that has been examined in order to determine the functional role of the relative marker within its clause is the occurrence of resumptive pronouns, also known as shadow pronouns. A resumptive pronoun represents the relativised NP within the relative clause on top of a clause-initial relative marker. It surfaces in the logical position of the relativised constituent, i.e. it is in the same position as a wh-trace. The following example is taken from Hermann (2003:48):

(27) Well, it's what they fed, you used to put it [i.e. treacle, T.H.] on hay that it was mouldy [...]

Radford states that resumptives only occur with the relative marker that but not with wh-pronouns. He provides the following examples (1988:484). The grammaticality judgements are his:

(28) a *He is someone $\mathrm{i}$ whom $\mathrm{i}$ you never know whether to trust him $\mathrm{i}$ or not

b $\% \mathrm{He}$ is someone $\mathrm{i}$ that you never know whether to trust him $\mathrm{i}$ or not

9 The vagueness of the argument is also supported by some cross-linguistic evidence. As Seppänen observes, the German indefinite pronoun man is not only unable to be preceded by a preposition (Ia); it cannot even be the object of a verb (Ib) (2004:77). Still, the word's pronominal status is unchallenged:

(I) a Was kann man tun, wenn die anderen *mit man / mit einem nicht reden wollen?

b Was kann man tun, wenn die anderen *man / einen nicht mögen? 
Radford argues that when a wh-pronoun is preposed, the gap/trace it leaves cannot be refilled with a pronoun. He concludes that if in a that-relative a pronoun is acceptable in the original position of the relativised element, then there cannot have been movement. In other words, that cannot be a preposed NP but must be a complementiser.

However, Radford's analysis leaves a number of important factors unconsidered. It may be true that (28a) is not found in English but that need not be due to any derivational difference between that-relatives and wh-relatives. Resumptive pronouns are typical of non-standard English while the case-marked wh-pronoun whom, which we find in his particular example, is a characteristic of very formal English. Thus, the ungrammaticality of (28a) is likely to be due to the nonoccurrence of the combination of these two styles. One might even expand that argument to $w h$-pronouns in general, which in many varieties are confined to formal speech, which is very carefully monitored and thus less likely to allow for nonstandard phenomena such as resumptives (Miller 1988:116). Nonetheless, grammaticality judgements on relatives combining a wh-pronoun and a resumptive differ. For van der Auwera, (29) is no less grammatical than a that-relative containing a resumptive (1985:156):

(29) I have to type the footnotes and the bibliography which I don't know how long they're going to be

The syntactic status of which in sentences such as (29), on the other hand, is subject of a discussion similar to that of relative that. While for van der Auwera and Hermann (2003:168ff) which is clearly pronominal here, Miller argues that these occurrences of which indicate that the word has developed a second function as a conjunction, not representing any antecedent but merely linking two clauses (Miller 1988:116; 1993:113).

In contradistinction to Radford, Hermann states that resumptives occur even more frequently with $w h$-pronouns than with that. In her view, the distribution of resumptive pronouns in that-relatives and $w$-relatives has nothing to do with any derivational differences between the two types of relative clauses. She argues that dialect speakers seek the support of a resumptive primarily in unfamiliar and difficult syntactic environments, such as non-restrictive relative clauses. Since nonrestrictives are usually introduced by a $w h$-pronoun while most restrictives are introduced by a particle, one of which is that, the overall number of $w h$-pronouns is higher than the number of thats in clauses containing a resumptive. Leaving non-restrictives aside, Hermann's results are closer to Radford's thesis because in restrictive clauses, resumptives occur more frequently with that than with $w$ hpronouns. However, her explanation is totally different from Radford's: She argues that resumptive pronouns combine more often with particles than with whpronouns because wh-pronouns are more explicit than particles. In other words, 
while $w h$-pronouns can inflect for case, animacy, and number, particles are sometimes felt to be in need of a resumptive to create an adequate link between antecedent and relativised element (ibid: 158).

Similarly to Radford, Stahlke (1976:599) tries to prove that there is a structural difference between $w h$-relatives, which involve $w h$-movement, and that-relatives, which do not involve $w h$-movement, by showing that the former are subject to the coordinate construction constraint while the latter are not. He compares (30a) and (30b):

(30) a The cops finally caught the man $i$ that Harry accused him $i$ and Pete of robbing the bank

b *The cops finally caught the man $\mathrm{i}$ who $\mathrm{i}$ Harry accused and Pete of robbing the bank

However, the contrast between these two sentences does not prove anything about that. The that-relative in (30a) contains the resumptive pronoun bim, whereas the $w$-relative in $(30 \mathrm{~b})$ does not contain a resumptive. Without the resumptive, however, (30a) will be as ungrammatical as (30b). Reciprocally, after insertion of the resumptive pronoun him in (30b), its grammaticality will be close to that of (30a). In short, it is the resumptive pronoun that is responsible for the asymmetry between the two sentences, not the relative marker.

Haegeman states that a wh-pronoun, when it co-occurs with a resumptive, "must be base-generated in [Spec,CP], i.e. it does not move into that position" (1991:373). She concludes that if no movement is involved, the subjacency condition should not come into play. Haegeman observes that many speakers of English use resumptives to avoid violations of the constraints on $w h$-movement. (31a) shows a violation of the complex NP constraint; (31b) shows how it can be overcome using the resumptive pronoun strategy (ibid:370;373):

(31) a *This is the man whom i Emsworth made the claim that he will invite

b This is the man $\mathrm{i}$ whom i Emsworth made the claim that he will invite him $\mathrm{i}$

Considering Haegeman's theory on base-generated relative pronouns, it is valid to assume that in (30a) relativisation is grammatical because that is a base-generated pronoun while in (30b) relativisation is ungrammatical because the movement of who violates the coordinate structure constraint. In any case, Stahlke's sentences fail to prove any structural difference between that and who.

Smith only mentions the combination of that plus resumptive and says that it also occurs in standard language in constructions of the form such that, which shows that relative that is a conjunction (Smith 1982:80): 
(32) This is a problem $i$ such that nobody can solve it i

That in (32) is clearly not a pronoun but a conjunction. The trouble is, however, that the subordinate clause is not necessarily a relative clause. Such is not necessarily a noun here. According to the OED ${ }^{10}$ there is a usage of such followed by a dependent clause introduced by that where "such tends to be intensive = so great, etc". It is reasonable to assume that meaning for the occurrence of such in (32) and to treat that as a consecutive conjunction introducing the sentence that denotes the effect produced by the "greatness" of the problem. In short, the occurrence of that in (32) is not an example of relative that.

Seppänen illustrates the structural and perceptual difference between a relative clause and a consecutive clause by providing some diachronic data. He argues that during the Early Modern English period there was a drop in the use of resumptive pronouns, which affected sentences such as (33):

(33) They presented some facts that only Peter could understand them $(>\varnothing)$

By contrast, constructions such as (34) remained unchanged:

(34) They presented such facts that only Peter could understand them $(>* \varnothing)$

Seppänen argues that that in (34) was taken to be a conjunction so that the pronoun was not a resumptive one and was thus retained. By contrast, in (33) that was perceived as a pronoun, exactly as which would be, making the pronoun them a resumptive pronoun and thus redundant (1993:71).

\subsubsection{Coordination of Which and That}

A synchronic argument in support of the structural likeness of that and which comes from Sag, who observes that that-relatives, unlike bare relatives, freely coordinate with which-relatives (Sag 1997:32; see also Kim and Sells 2008:234):

(35) a *Every essay she's written and that/which I've read is on that pile.

b Every essay which she's written and that I've read is on that pile.

c Every essay that she's written and which I've read is on that pile.

The coordination rule requires two identical phrases to be conjoined. In (35b) and (35c) coordination is grammatical, whereas in the unacceptable example (35a), two

10 Oxford, Clarendon Press, 1970, vol. 10, p.86. 
different constituents, one with a gap value and one with no gap value, are conjoined (ibid). Thus, coordination data indicates that that and which are syntactically identical.

\subsubsection{The Doubly Filled COMP Filter Revisited}

The doubly filled COMP filter states that the sequence of an overt wh-element under $[\mathrm{SpecCP}]$ and an overt complementiser under $\mathrm{C}^{0}$ is ungrammatical. However, the filter does not always apply. In the following sentence, that takes the $\mathrm{C}^{0}$ position and the $[\mathrm{SpecCP}]$ position is occupied by an overt a wh-element. The example is taken from Seppänen and Trotta (2000:171):

(36) You would be more inclined to say that this is the outfit who that could live more easily with its second string

The sentence in (36) is an example of what has become known as the "wh+that Pattern" (ibid:161). The pattern was a prominent feature in earlier stages of the language when that was a general marker of subordination and optionally followed subordinating conjunctions, interrogative words in indirect questions, and relative pronouns. Smith says that $w h+t h a t$-relatives appeared in the $14^{\text {th }}$ century and had generally disappeared by the end of the $15^{\text {th }}$ century (1982:60-61).11 He presents a Middle English Example of the pattern:

(37) And gladly heare good sawes, Which that good men us shawes

The wh+that pattern has been influential on transformationalist descriptions of subordinate clauses: Klima assumes that in their D-structure representation all relative clauses begin with $w h+t h a t$, which "has historical justification" (1964:6). Radford, too, supports his analysis of that-relatives as a sequence of an empty $w h$ operator followed by the overt complementiser that by referring to Middle English $w h+$ that-patterns (2006:146). Yet, in present day English the wh+that pattern only plays a very marginal role in bound relative clauses (Seppänen and Trotta 2000:172).

However, an environment in which it is still (or again) frequently found is free relative clauses and Seppänen argues that this contrast supports the analysis of that as a pronoun (2000:44). Free relatives are also known as fused relatives because instead of having a sequence of two distinct elements, antecedent and relative word are "fused" into one element:

11 See section 5 for more information on the history of relative that. 
(38) I ate whatever was left

In (38), whatever combines the functions of the antecedent within the matrix clause and the function of the relative pronoun serving as subject within the relative clause. Seppänen argues that that appears in structures like these more frequently and naturally because the sequence whatever that can be interpreted as the sequence of an antecedent head in a matrix clause followed by a relative pronoun introducing a relative clause, making the free relative structurally identical to a bound relative (ibid):

(39) whatever that was left

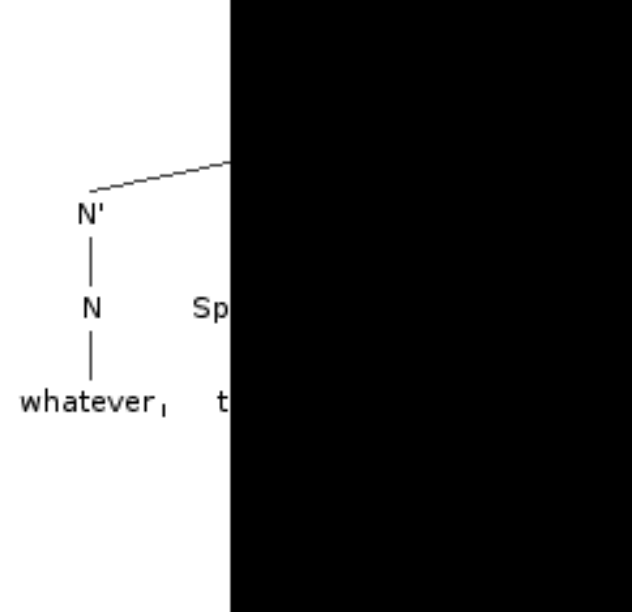

He supports his theory by presenting the following examples in which that is replaced by a $w h$-pronoun (ibid):

(40) a $[\ldots]$ the husband the wife the children whoever who was involved in that family living in a house should earn money.

b $[. .$.$] whatever ordeal into which she had to lead the rest ... was al-$ ways rewarded by authority's approval

Consequently, the examples in (39) and (40) are not to be treated as examples of doubly filled complementisers.

In sum, then, the $w h+$ that pattern in present day English does not justify an identification of relative that with the complementiser. On the contrary, it supports the existence of two lexical items, a complementiser that and a relativiser that. In bound relatives, where that can only be a complementiser under $\mathrm{C}^{0}$, the occurrence of the pattern is scarce, the doubly filled COMP filter proves valid in the majority of cases. By contrast, that frequently occurs after wh in free relatives, 
which sequence can be taken to be that of an antecedent head in a matrix clause followed by the relative proform that in [SpecCP]. That analysis is supported by the fact that that in these structures is in the same distribution as undisputed relative proforms.

The validity of the assumption that relative that occupies [SpecCP] is further supported by the existence of a different type of doubly filled COMP: Seppänen argues that in the following if-clauses the word if occupies the $C^{0}$ node (2000:46). In (41a) it is preceded by which, which occupies the [SpecCP] position. In the structurally analogous (41b), it is preceded by relative that, which must consequently occupy the same position (2000:46):

(41) a This standard figure is called Bogey, which if you have beaten $[t]$ you are a good player

b Write a list down of all the animals that if you ran over [ $t$ you'd have to report to the police

\subsection{Sentential Distribution}

\subsubsection{Tenseness}

It is a typical feature of complementisers to subcategorise for either finite or nonfinite clauses. In English, the subordinator that selects finite clauses as its complement, while the complementiser for selects infinitival clauses. The following examples come from Haegeman (1991:107):

(42) a I think that Poirot b

(43) a I expect for Poirot b

$\begin{array}{ll}\text { abandoned } & \text { the investigation } \\ \text { *to abandon } & \\ \text { to abandon } & \text { the investigation } \\ \text { *abandoned } & \end{array}$

*abandoned

By contrast, wh-pronouns occur in both finite and infinitival clauses.

(44) a He had no one on whom to rely

b He had no one on whom he could rely

It is often argued that that occurs in finite relative clauses only, which dismisses the pronoun analysis and supports the identity of relative that and complementiser that (Radford 1988:483; Stahlke 1976:592; Huddleston and Pullum 2002:1057). The following example is taken from Huddleston and Pullum (2002:1057):

(45) *a knife that to cut it with 
The force of the argument is diminished by the fact that in (45), which cannot appear, either. Infinitival relatives do not allow for preposition stranding but require the preposition to be preposed (Huddleston and Pullum 2002:1057; van der Auwera 1985:166). Van der Auwera states that that cannot appear in structures such as (45) because it does not allow pied piping and not because they are infinitival (van der Auwera 1985:166).

The difference between that and $w h$-words, as far as their distribution in finite and infinitival clauses is concerned, is not as clear-cut as it first appears. As noted earlier in the section on upward perlocation, Miller observes that in natural spoken language "infinitive relatives have no wh-relativiser" (1988:115). Moreover, Seppänen presents examples where that does occur in infinitival relative clauses (2003:269-370):

(46) a old Arthur Gride and dark eyes and eyelashes, and lips that to look at is long to kiss (Dickens: The Life and Adventures of Nicholas Nickleby, Chapter 47)

b That is a paper which / that to be seen with I am afraid might brand you as politically suspect

c There are things in it which / that to repeat might be considered inappropriate.

The sentences in (46) may not be accepted by all speakers, but in any case they are considerably more acceptable than (42b). This shows that there is a difference between the complementiser that and the relativiser that. In fact, the existence of sentences such as (46) is detrimental to the complementiser analysis of relative that. For Haegeman, it is criterial to a complementiser that it imposes selectional restrictions on the finiteness of its complement IP. In her view, for example, "whether is not the head of CP but is a wh-phrase in the specifier of CP. Like other wh-phrases in [Spec,CP] it is compatible with both finite and non-finite clauses" (1999:175). Considering the sentences in (46), relative that, too, has to be treated as a $w h$-phrase in the specifier of CP rather than as a head of CP.

\subsubsection{Restrictiveness / Nonrestrictiveness}

Stahlke says that if that were a pronoun, it should parallel the behaviour of undisputedly pronominal wh-elements. However, while who and which can occur both in restrictive and appositive relative clauses, that can only appear in restrictive clauses (1976:588):

(47) a *The vice president, that was appointed by Ford, has placed the State of New York under trusteeship 
b The vice president, who was appointed by Ford, has placed the State of New York under trusteeship

Yet, that argument does not prove any structural difference between $w h$-pronouns and that. It is not true that that only introduces restrictives (Hermann 2003:104; van der Auwera 1985:155; Smith 1982:75). Smith supposes that that is less likely to occur in appositives because they more often involve human antecedents and that is marked for non-humans for a number of speakers (1982:71). Markedness for animacy contradicts rather than supports the complementiser analysis. Another argument for the misbalanced distribution of that is that appositives are connected more loosely to their antecedent, which requires the relative marker to be more explicit, e.g. to be clearly gender-marked and/or casemarked (Hermann 2003:52; van der Auwera 1985:155). Lastly, it is controversial in how far any limitation of that to restrictives should be related to its status as a complementiser.

\subsection{Omissibility}

\subsubsection{Subject Relatives: EPP vs. Ambiguity Avoidance}

Proponents of the complementiser analysis have argued that relative that deletes under the same conditions as the complementiser that. By contrast, supporters of the pronoun analysis have argued that the word deletes under the same conditions as who(m) and which do.

An argument often put forward to promote the pronoun analysis is that if that were a conjunction, that-relatives with a relativised subject would lack an overt subject and thus violate the Extended Projection Principle. Van der Auwera argues that zero-subjects in English are highly restricted and usually limited to existential constructions and topicalisation structures, such as it-clefts (1985:160):

(48) a There's a man wants to talk to you

b It's Peter wants to talk to you

On the other hand, proponents of the complementiser analysis have argued that subject-less clauses are not as restricted as van der Auwera argues, that "subjectless verbs are not the syntactic catastrophe that they might seem to be" (Smith 1982:78).

Stahlke states that the following sentences are acceptable in non-standard English (1976:597): 
(49) a The man married my sister is a lawyer

b Any man believes such a thing must be a fool

Moreover, there are subject-less relative clauses introduced by the conjunctions as and but (van der Auwera 1985:161; Smith 1982: 86; Jespersen 1927:168182):

(50) a He's a man as likes his beer

b There was not one but had been guilty of some act of oppression

The above examples show that finite relative clauses do not need to have an overt subject. Moreover, they indicate that conjunctions may be a structural means of introducing relative clauses. ${ }^{12}$ The observation that finite relative clauses need not always have a subject clearly invalidates the thesis that that must be pronominal for the simple reason that if it were a conjunction, that-relatives would be subject-less and their grammaticality would be inexplicable.

Nevertheless, the existence of bare subject relatives does not provide any positive evidence supporting the conjunction analysis because there is no reason why zero-subject-relatives are any more an absence of that than of a wh-pronoun (van der Auwera 1985:160). The existence of other relative conjunctions may show that conjunctions are a structural means of relativisation in English but it does not prove anything about the syntactic status of relative that. Lastly, at least in Standard English, subject relatives are not bare so that that deletes under the same conditions as who(m) and which.

Stahlke's overall claim is that " $\mathrm{t}]$ he deletion of the conjunction that is subject to the same perceptual and semantic conditions, whether it introduces a relative clause or a complement" (1976:609). One of these perceptual and semantic conditions is ambiguity avoidance. Huddleston and Pullum state that both relative that and complementiser that are more likely to be omitted in short structures than in long ones (2002:1053). However, this does not prove anything about the relativiser because the absence of relative that could as well be the absence of a $w h-$ pronoun

They also argue that the prohibition on deleting that has nothing to do with its grammatical function as subject but that it is associated with the need to distinguish the subordinate clause from the matrix clause, i.e. with the need to avoid "misconstruals" (ibid: 1055). Their argument is that sentences such as (50) are ungrammatical or at least clearly non-standard because there is nothing to prevent the listener from construing the relative clause predicate as the main clause predicate (ibid).

12 Their syntax, however, is subject of a discussion similar to the current discussion of relative that (e.g. see van der Auwera 1985:161). 
That way, relative that parallels the complementiser that, whose deletion, too, is determined by ambiguity avoidance (Temperley 2003:464). In (52a) there is nothing to prevent the listener from construing the subordinate clause as the main clause:

(51) a *John is sick is quite evident.

b That John is sick is quite evident.

Nonetheless, for a lot of speakers the omission of that is not insensitive to its function as subject, with ambiguity avoidance being the decisive factor: Ambiguity does not arise in all kinds of bare subject-relatives. For example, when a bare subject-relative modifies the direct object of its matrix clause, there is no ambiguity at all:

(52) *I met the woman likes John

Temperley and Stahlke note that the difference in potential ambiguity does lead speakers to favour some types of bare subject relatives over others in nonstandard language (Temperley 2003:483; Stahlke 1976:598) but for a lot of speakers, even the unambiguous (52) is unacceptable. That that does in fact function as subject is also supported by the observation mentioned above, that the word is only used with singular verbs when referring to collective nouns and sometimes occurs with a singular verb even when referring to a singular antecedent, which means that it shows subject-verb-agreement.

The theory that the deletion of that depends on the avoidance of structural ambiguity may explain the fact that relative markers are required in subject but not in object relatives. But within the group of subject relatives it is not quite appropriate for many speakers. Bare subject relatives are restricted irrespective of whether they are structurally ambiguous at some point in their interpretation. Of course, that does not entail that that itself functions as subject. To remain faithful to the conjunction analysis of that and to the principle of ambiguity avoidance it may be argued that subject relatives in general are more likely to be ambiguous and therefore always require the insertion of the subordinating conjunction that.

However, it will then still be true that that deletes under the same conditions as $w h o(m)$ and which so that no formal difference between those $w h$-pronouns and that can be derived from the asymmetry in omissibility between subject and nonsubject relatives.

\subsubsection{The That-Trace Effect}

While the deletion of that in relative clauses neither disproves the conjunction analysis nor the pronoun analysis, there is a rule governing its deletion in comple- 
ment clauses which reveals a crucial difference between relative that and complementiser that. Haegeman illustrates the rule by comparing (53a) and (53b) (1991:362).

(53) a *the letter that John said that would surprise Poirot
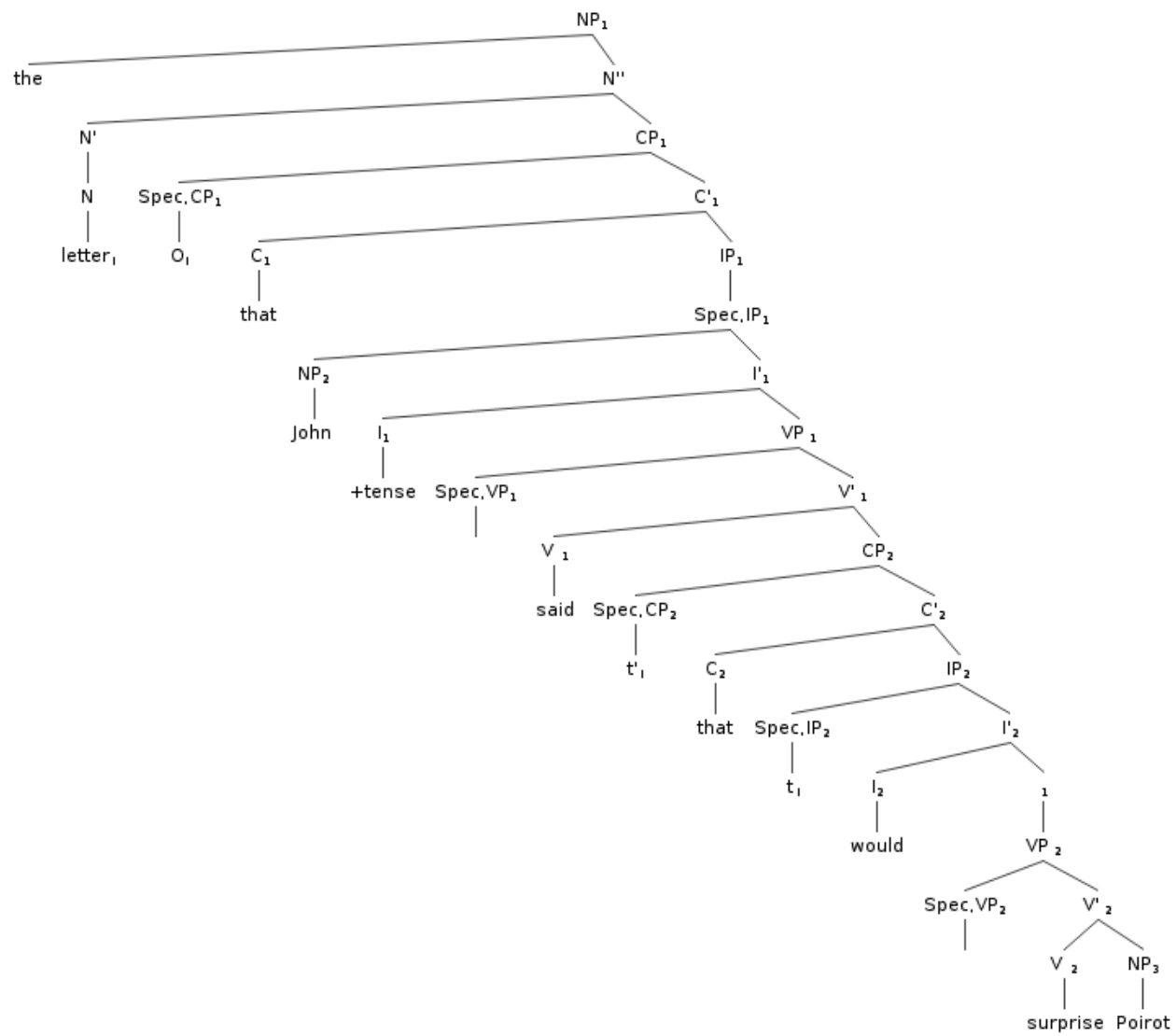

b the letter that John said $\varnothing$ would surprise Poirot

In (53), the subject has been relativised using the empty operator, leaving the trace $t$ ' in its original position in [SpecIP2]. The ECP, which requires that all traces be properly governed, is not satisfied in (53a). The overtly realised complementiser in CP2 prevents the trace $t$ ' in IP2 from being properly governed. In (53b), where there is no overt complementiser, the subject can be extracted from the lower clause. Chomsky and Lasnik (1977) and Haegeman (1991) capture that obser- 
vation by means of the That Trace Filter stating that "[ $t$ ]he sequence of an overt complementiser followed by a trace is ungrammatical" (Haegeman 1991:362). Thus, subject relatives introduced by that, too, should be ungrammatical if the element that were the same lexical item as the complementiser, as presented in (54):

(54) the letter that will surprise Poirot

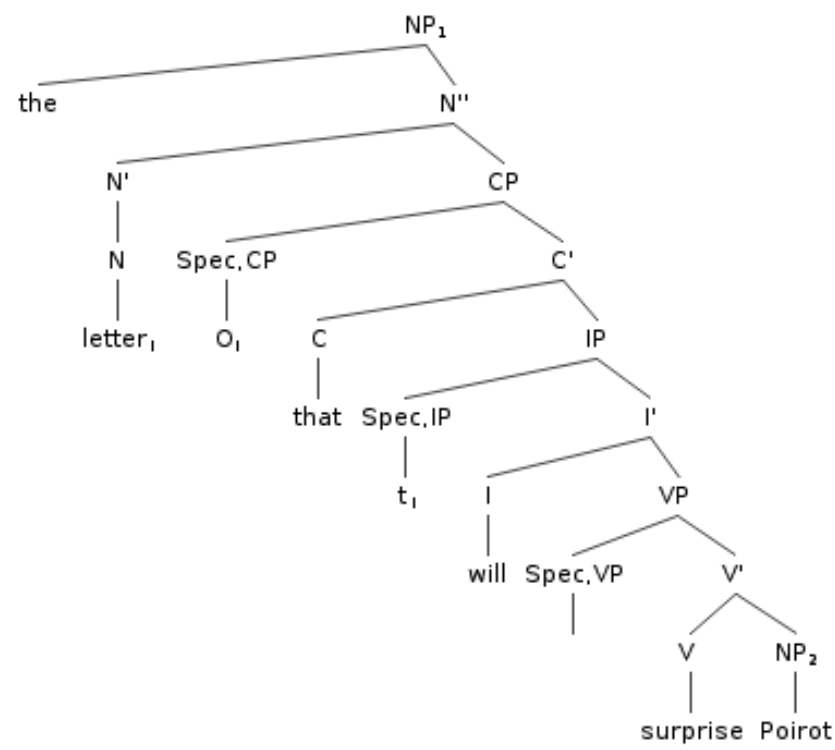

To account for the grammaticality of (54), Haegeman uses a rule introduced by Pesetsky (1982:306). The rule merges the empty operator and the complementiser into one element when they are adjacent to each other. As a result, that is assigned the coreferential index of the operator and is thus able to antecedent-govern the trace instead of blocking antecedent-government. Nonetheless, the element is still different from the $w h$-pronouns in that it stays under $\mathrm{C}^{0}$ (Seppänen 2000:40). After "complementizer contraction" (Haegeman 1991:424), the S-structure of (54) is as in (55): 
(55) the letter that will surprise Poirot

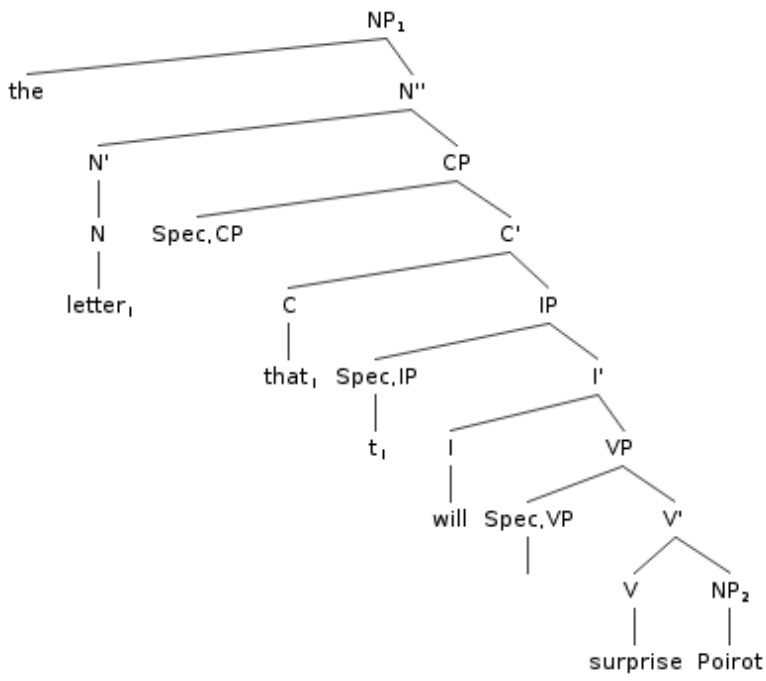

According to Haegeman, in (53a) complementiser contraction can only apply to the complementiser that heads CP1. Relying on adjacency to the operator, it cannot apply to the complementiser heading CP2. Therefore it keeps on blocking government from the trace $t$ and makes the sentence ungrammatical. The result of the contraction rule corresponds to the traditional distinction between the relative pronoun that and the complementiser that. The first that in (53a) is an occurrence of the pronoun, whereas the second that is an occurrence of the complementiser introducing the sentential complement of the verb say.

The that-trace effect is a phenomenon that is inconsistent with the analysis of that as being identical with the complementiser, and the phenomenon has widely been left unconsidered in the discussion of relative that. Haegeman's and Pesetsky's handling of the problem is not convincing. Seppänen sharply criticises "the blatantly ad hoc nature of the rule" (1993:372), calls it "theoretically awkward" (2000:40) and says it works "in a purely technical sense" (1993:372).

\subsubsection{Illocutionary Force of the Clause}

Stahlke argues that that is the subordinator for factive sentences so that the word cannot be deleted if the subordinate clause is the complement of a factive verb (1976:598):

(56) a It occurred that the captain had lost his orders

b *It occurred the captain had lost his orders

c It occurred to me the captain had lost his orders 
He argues that the content of a relative clause is always presupposed to be true or at least declarative unless the head NP is generic or the clause contains a modal. He illustrates that observation e.g. by showing that the verb in the relative clause has to be in indicative mood (ibid: 608):

(57) a A person that lives in a grass house should not stow thrones

$\mathrm{b} * \mathrm{~A}$ person that live in a grass house should not stow thrones

He suspects that the insertion of that is to indicate the factive/declarative character of a relative clause (ibid). However, his argument is questionable. His examples in (56) illustrate that factive complement clauses are ungrammatical without that. By contrast, relative clauses that do not contain that will have the same illocutionary force (58b) and will still be grammatical (58a):

(58) a A person who lives in a grass house should not stow thrones

$\mathrm{b} * \mathrm{~A}$ person who live in a grass house should not stow thrones

Hence, Stahlke's observation reveals a difference in omissibility between relative that and complementiser that rather than a shared property. Moreover, as Smith observes, Stahlke's argument does not hold because complementiser that can also be used non-factively (1982:76):

(59) I demand that he live in a grass house

\subsubsection{Enhanced Restrictiveness}

Both that and $\varnothing$ are used to introduce restrictive relative clauses. Stahlke observes that that will not be deleted "if there is some need to 'enhance' restrictiveness" (1976:607). In other words, that-relatives are more restrictive than Ø-relatives:

(60) a If we have any thought for the good of the company, the only man $\varnothing$ we can assign to advertising is Smith.

b There are several interested, but the only man that we can assign to advertising is Smith; the others can't be spared from their present posts

The semantic concepts of restrictiveness and enhanced restrictiveness are specific to relative clauses so that there is no equivalent in the case of complementiser that. 


\subsubsection{Summary}

Since both relative that and complementiser that function to indicate subordination, the omission of both is influenced by the need to distinguish the main clause from the subordinate clause; i.e. their omission is subject to the principle of ambiguity avoidance. Apart from that, relative that and complementiser that delete under different conditions. Factors influencing the omissibility of relative that and complementiser that are complex and numerous; the above examples do not cover the whole range. ${ }^{13}$ However, they suffice to indicate that the conditions are specific to the different syntactic and semantic contexts in which that is used, i.e. they arise from its status as either relativiser or complementiser (in the narrow Rosenbaum sense). Syntactically, at least in Standard English, relative that cannot be deleted in subject relatives whereby it parallels $w h o(m)$ and which rather than complementiser that. If despite that fact, that in subject relatives is considered to be a conjunction, it must be in the position before the subject gap, which is a position from which the complementiser that must be omitted. That way, relative that would be an exception to that rule if it were the same lexical item. Semantically, too, the two thats are different: Relative that cannot be deleted when there is a need to express a sense of enhanced restrictiveness, which is a concept that is not at issue in a complement clause. On the other hand, the deletion of the complementiser is sensitive to the illocutionary force of its clause, which is a piece of semantic information that is not at issue in a relative clause.

\subsection{Proform for PPs and NPs}

That does not only relativise nominal constituents but also represents constituents equivalent to a relative adverb or a sequence of a preposition and a relative pronoun:

(61) The place where / to which / that we went

It has been suggested to treat all occurrences of relative that as occurrences of a conjunction because "[that] would be the only pronoun capable of replacing either an NP or an adverb" (Stahlke 1976:590). Nonetheless, Van der Auwera observes that the particular example in (61) makes that less non-pronominal than appears at first sight. The noun place, unlike the noun street, can head a bare adverbial NP so that that does not necessarily represent a PP in (62) (1985:174):

13 Van der Auwera argues that the omission of the complementiser is influenced by the frequency of the main verb and by the presence of an indirect object. He also provides bibliographic details for further information on the omission of relative that and complementiser that (1985:160). 
(62) You have been some place/*street

Larson (1983) argues that the use of that is restricted to nouns like that, which supports the pronominal quality of the word (van der Auwera 1985:175):

(63) a I saw the place that / in which John lived

b I saw the street *that / in which John lived

Van der Auwera agrees to the extent that that may be particularly frequent with bare NP adverbials but he objects that there is no absolute restriction to those. He cites cases in which that does represent PPs (ibid):

(64) I saw Fred in the street that / in which John lived

Van der Auwera proposes that there are two different relative thats: a relative pronoun and a relative adverb (1985:157). However, relative that is very different from typical relative adverbs as far as the semantic concord with its antecedent is concerned. Relative where typically takes locative expressions as antecedents. When and while are confined to temporal expressions, and why only takes the antecedent reason. In sharp contrast to this, relative that covers the ground of all those words put together:

(65) a The reason why/that/*where/*when/*while (for which) I went home

b The time while/when/that/\%where/*why (during/in/at which $)^{14} \mathrm{I}$ stayed at home

c The place where/that/*while/*when/*why (to which) I went

Nonetheless, the above examples only show that relative that is not always used as a pronoun. They do not deny its status as a proform, nor do they prove the complementiser analysis. Due to space constraints a more detailed analysis of that as a PP-relativiser cannot be done in this paper.

\section{Diachronic Excursus: On the History of Relative That}

Although diachronic data has little bearing on the status of present-day relative that, I will give a brief survey of the history of the word to shed some additional light on its peculiar syntactic properties. Overall, the history of relative that is as

14 Relative while is not accepted by all speakers in bound relatives. Compared to relative when, it is more likely to be used to denote duration rather than a point in time. Considering that relative adverbs are sensitive to those refined semantic differences, the contrast between those adverbs and relative that becomes even bigger. For a comprehensive study of relative while see Trotta and Seppänen 1998. 
controversial as its current syntactic status. Some scholars trace it back to the Old English pronoun pat; others view it as going back to the subordinating conjunction pat. As in the case of the synchronic analysis, there are also inbetween positions considering the relativiser to go back to both sources.

Old English had a paradigm of relative pronouns se, seo, pat (masc., fem., neut. nom. sing.) inflecting for nominative, genitive, dative, accusative, and instrumental case, inflecting for masculine, feminine, and neuter gender, and inflecting for singular and plural number. They could only occur with pied piped prepositions. The form pat was nominative and accusative neuter singular (Smith 1982:44-46).

Apart from that paradigm of pronouns, Old English had the relativiser pe, which always stranded its preposition (Dekeyser 1988:164), which was indeclinable, and which is therefore generally considered non-pronominal. ${ }^{15}$ There was also a rare type of relative clause combining a form of the relative pronoun with pe in the form of sepe, seope, pactee.

From the $9^{\text {th }}$ century on, pat started to lack inflection (van Gelderen 2004:73). It started to violate gender and number concord, began to strand its preposition and appeared in the form pat instead of taking the case required by the preposition (Smith 1982:46). Smith argues that this lack in concord marked the change from pronoun to complementiser, with pat going through an intermediate stage in which it was sometimes a pronoun and sometimes a complementiser (ibid). Seppänen objects that the "deviant" use of pat is not an indication of its transformation into a conjunction because it was still mainly confined to neuter heads, temporal heads and the antecedent eall, thus showing semantic concord (2000:35).

The general complementiser in Old English was pat, used to introduce complement clauses like Modern English that. Smith argues that relative pat merged with that complementiser when it became indeclinable and stopped preposition fronting (1982:46) whereas Seppänen says that the pronoun was preserved (200:48).

Either way, the invariant form that came to replace the entire paradigm se, seo, pat by the Early Middle English period (1100-1250). The form was first confined to inanimate antecedents, alternating with $p e$, which occurred after animate antecedents. Ultimately that took over all functions of pe (Smith 1982:55) so that by the beginning of the Mid Middle English period (1250-1350), that was the only relative marker and was used after any antecedent (ibid:53).

From the $12^{\text {th }}$ century on, that appeared after the conjunction giff (if) in conditional and indirect clauses and by the $14^{\text {th }}$ century that had been generalised as a marker of subordination. It could follow subordinating conjunctions and whpronouns, which had entered the language in the Late Middle English period (1350-1500), in indirect questions, free relatives, and bound relatives. The

15 Dekeyser (1988:163), Stahlke (1976:587), Van der Auwera (1985:172), van Gelderen (2004:71) consider pe non-pronominal. Seppänen (2000:31) says that the word was also used pronominally. 
$w h+$ that pattern in bound relatives structurally corresponds to the Old English sepe, seope, patpe relatives since both are considered a sequence of a pronoun in [SpecCP] followed by a complementiser in $\mathrm{C}^{0}$.

Middle English wh+that-relatives strongly favour the complementiser analysis of relative that. Van Gelderen assumes that that moved from [SpecCP] into $\mathrm{C}^{0}$, when it was taking over all functions of $p e$, which she considers to have occupied that position previously (2004:72).

On the other hand, Seppänen cites occurrences of a that that pattern in Middle English as well as instances of that being preceded by a preposition, which indicates that the pronominal use of that was still preserved (2000:32-33) and that that did at least not in all cases move from [SpecCP] into $\mathrm{C}^{0}$. In addition, although supporting the complementiser analysis, van Gelderen observes that Middle English rlative that sometimes triggered "wrong" agreement in that it took singular verb forms although having a plural antecedent. According to her, that was a reflex of the Old English Pronoun pat, which was confined to singular heads (2004:76). As stated above, she argues that this phenomenon has been preserved until today. That observation encourages that that was not always a head in $\mathrm{C}^{0}$ but sometimes a pronoun in $[\mathrm{SpecCP}]$ and thus subject to agreement. Seppänen argues that Middle English had a relative complementiser in $\mathrm{C}^{0}$ and retained the Old English pronoun that in [SpecCP]. According to him, the former was then re-analysed as a pronoun so that all occurrences of modern English relative that are pronominal; however, with the peculiarity of being able to occur in either of the syntactic positions (2000:46).

The $w h+$ that pattern had disappeared by the end of the $15^{\text {th }}$ century (Smith 1982:60-61). Several reasons for its decline have been suggested. Van der Auwera argues that relative that does not go back to the Old English pronoun but to the coalescence of the Old English non-pronominal relativiser pe and the complementiser pat and has since undergone a process of pronominalisation. That process eventually made the pattern redundant (1985:174). Smith, who promotes the opposite argument saying that the relative does go back to the Old English Pronoun but has become a complementiser, presents a number of possible reasons for the loss: He argues that wh and that may have semantically reinforced each other so that they were perceived as a compound-relative marker, which was later simplified into either that or $w h$. The pattern may also have conflicted with the emerging rule that that be the clause-initial complementiser. Another reason Smith mentions is word order: When subject-verb-inversion became restricted to interrogatives and thus no longer applied to relatives, the insertion of that was no longer necessary to distinguish interrogatives from relatives, which were introduced by the same set of $w h$-words (Smith 1982:64).

In sum then, there are numerous different positions: Van der Auwera and Stahlke doubt that relative that is historically a pronoun (Stahlke 1976:587; Van der Auwera 1985:174). However, while Stahlke argues that today it is still not a 
pronoun, van der Auwera states that it has become "highly pronominal" (1985:171). Seppänen not only argues that the Old English pronoun is still preserved but he also argues that the Middle English relative conjunction that has been re-analysed as a pronoun, from which it inherits the peculiar characteristic of being unable to follow a preposition (200:48). Lastly, Smith and van Gelderen trace relative that back to the Old English pronoun and say it has changed into a complementiser (Smith 1982:46; van Gelderen 2004:72).

\section{Conclusive Summary}

Relative that and complementiser that may share the same phonological (and orthographical) shape but they are two different lexical items. Relative that is a $w h$ operator but it shows a number of peculiarities.

Proponents of the complementiser analysis have mainly based their view on the formal identity between the relativiser and the complementiser that, on the morphological invariance of relative that, on its non-occurrence in infinitival relatives, and above all on its inability to be the complement of a preposition. On the other hand, the traditional pronoun analysis has rested on the functional resemblance between relative that and $w$ h-pronouns as well as on their great distributional similarity.

In this paper I have tried to consider various varieties of English, such as standard language, non-standard language, and different regional dialects. It has been shown that there is little stability in the use of relative that but the validity of all arguments in favour of the complementiser analysis has been challenged at some point: That has an oblique form that's in a number of dialects, that does occur in infinitival relatives, and its inability to follow a preposition does not consistently discriminate the word from other $w h$-operators.

In formal English, relative that shares the wh-typical characteristics of being gender-marked and being subject to the rule that it not be deleted in subject position. It cannot immediately follow a preposition, but neither can who and what. Data from spoken English further alleviates the contrast between that and whpronouns in that pied piping is less typical with wh-pronouns, wh-pronouns are less explicit, and that occurs in both restrictives and nonrestrictives. Very strong syntactic arguments in support of the wh-analysis of relative that are the fact that that-relatives freely coordinate with which-relatives, the fact that relative that, exactly like which, can precede the word if in a conditional relative, the occurrence of that in infinitivals, and the development of a genitive that's and connectedly the development of a complex relative phrase containing the relativiser as a genitive attribute.

A wh-proform in any case, it is doubtful whether it is always a wh-pronoun: There is a usage of the relativiser being equivalent to a relative adverb or a sequence of a preposition and a relative pronoun. Apart from its structural 
versatility, the word is semantically very flexible, representing animate antecedents, inanimate antecedents and circumstantial elements, such as place, time, or reason.

Nonetheless, there is a clear difference between the relativiser and the complementiser that, which is closely associated with the different semantic and syntactic environments in which they occur, namely relative clauses and complement clauses.

Complement clauses do not contain a relativised element, they are not tied to any antecedent, and they are restricted to heads that C-select for it whereas a relative clause can modify nearly any antecedent head. Those who analyse relative that as being identical with the complementiser that do not deny the difference between those two types of clauses even though they may use the misleading term complementiser when referring to relative that (cf. e.g. Smith 1982:36-37). However, what they do believe is that it is the same lexical item that that is used to introduce those two very different types of subordinate clauses.

That claim, however, has been shown not to be without its difficulties. Strong arguments denying the identification of the relativiser with the complementiser are the fact that the complementiser selects for finite clauses while the relativiser is also found in infinitival relatives and the fact that the complementiser is subject to the that-trace-effect whereas the relativiser is not. The complementiser occupies $\mathrm{C}^{0}$ while the relativiser moves into [SpecCP]. This becomes apparent from the occurrence of the sequence of relative that followed by if in a conditional relative and its occurrence as a genitive attribute within a complex relative phrase. Moreover, that frequently occurs after wh in free relatives, which may be interpreted to offer an available $[\mathrm{SpecCP}]$, while it rarely occurs after $w h$ in bound relatives, where that position is not available.

Semantically, too, the complementiser and the relativiser differ. The complementiser does not have any referential quality while the relativiser is felt to refer back to an antecedent. Relative that cannot be deleted when there is a need to express a sense of enhanced restrictiveness, which cannot arise in a complement clause. On the other hand, the deletion of the complementiser is sensitive to the illocutionary force of its clause, which is a piece of semantic information that is not at issue in a restricive relative clause.

In sum then, relative that and complementiser that are two different lexical items. The relativiser that may both syntactically and semantically be the most versatile relativiser but still it is more similar to wh than it is to the complementiser. 


\section{References}

van der Auwera, Johan. "Relative That: A Centennial Dispute." Journal of Linguistics 21:1 (1985): 149-179.

Baker, Carl. Lee. English syntax. Second edition. Cambridge, MA/London: MIT Press, 1995.

Bergh, Gunnar and Aimo Seppänen. "Preposition Stranding With Wh-Relatives: A Historical Survey." English Language and Linguistics, 4:2 (2000): 295-316.

Chomsky, Noam and Harold Lasnik. "Filters and Control." Linguistic Inquiry 8 (1977): 425-504.

Dekeyser, Xavier. "Preposition Stranding and Relative Complementizer Deletion: Implicational Tendencies in English and the Other Germanic Languages." Leuvense Bijdragen: Lewven Contributions in Linguistics and Philology 77:2 (1988): 161181.

Fowler, Henry Watson. The King's English. Oxford: Clarendon Press, 1908; Bartleby.com, 1999. www.bartleby.com/116/. Accessed on 22. February 2008.

van Gelderen, Elly. "Economy, Innovation, and Prescriptivism: From Spec to Head and Head to Head." Journal of Comparative Germanic Linguistics, 7:1 (2004): 59-98.

Haegeman, Liliane. Introduction to Government and Binding Theory. Oxford: Blackwell, 1991.

Haegeman, Liliane M. V., and Jacqueline Guéron. English Grammar: A Generative Perspective. Oxford: Blackwell 1999.

Hermann, Tanja. Relative clauses in dialects of English - a typological approach. Freiburg, 2003.

Huddleston, Rodney \& Geoffrey K. Pullum. The Cambridge grammar of the English language. Cambridge/New York/Melbourne/Madrid/Cape Town: Cambridge University Press, 2002.

Jespersen, Otto. A modern English Grammar on historical principles. Part III. Copenhagen: Ejnar Munksgaard, 1927.

Kim, Jong-Bok and Peter Sells. English Syntax: An Introduction. Stanford: Center for the Study of Language and Information, 2008.

Klima, E. S. "Relatedness between grammatical systems." Language 40 (1964): 120.

Levin, Magnus. "Concord with collective nouns revisited." ICAME Journal 23 (1999): 21-33. 
Miller, Jim. "That: a relative pronoun? A Sociolinguistic and syntactic analysis." In: Edinburgh Studies in the English Language. Ed. Anderson and Macleod. Edinburgh: Donald, 1988.113-119.

Miller, Jim. "The grammar of Scottish English." In: Real English. The grammar of English dialects in the British Isles. Ed. James Milroy \& Lesley Milroy. London/New York: Longman, 1993. 99-138.

Pesetsky, David. "Complementiser trace phenomena and the nominative island condition." Linguistic Review 11 (1982): 297-343.

Quirk, Randolph, Sidney Greenbaum, Geoffrey Leech and Jan Svartvik. A comprehensive Grammar of the English Language. London/ New York: Longman, 1985.

Radford, A. Transformational Grammar: A First Course. Cambridge: Cambridge University Press, 1988.

Radford, A. Minimalist Syntax Revisited, 2006. http://courses.essex.ac.uk/lg/lg514, accessed on March 24, 2008.

Sag, Ivan A. "English Relative Clause Constructions." Journal of Linguistics 33 (1997): 431-483.

Seppänen, Aimo. "On the history of relative that." In: Generative Theory and Corpus Studies A Dialogue from $10 \mathrm{ICEHL}$. (Topics in English linguistics 31.) Ed. Ricardo Bermúdez-Otero, David Denison, Richard M. Hogg \& C. B. McCully. Berlin/New York: Mouton de Gruyter, 2000: 27-52.

Seppänen, Aimo. "The Old English relative pe." English Language and Linguistics 8 (2004): 71-102

Seppänen, Aimo. "The relatiye [sic] "that" reconsidered." In: Actes du XVe Congrès International des Linguistes, Québec. Ed. André Crochetière. Sainte-Foy: Université Laval, 1993: 369-372.

Seppänen, Aimo and Göran Kjellmer. "The Dog That's Leg Was Run Over: On the Genitive of the Relative Pronoun." English Studies: A Journal of English Language and Literature 76:4 (1995): 389-400.

Seppänen, Aimo and Joe Trotta. "The wh- + that Pattern in Present-day English." In: Corpora Galore: Analyses and Techniques in Describing English: Papers from the Nineteenth International Conference on English Language Research on Computerised Corpora (ICAME 1998). Ed. John M. Kirk. Amsterdam: Rodopi, 2000: 161-175.

Smith, Evan Shreeve. Relative 'that' and 'as': A study in category change. Ph.D. thesis, Indiana University. Printed in 1982 by University Microfilms International, Ann Arbor, MI.

Stahlke, Herbert. "Which that.” Language 52 (1976): 584-611.

Stahlke, Herbert. "Message 3: That's." The LINGUIST LIST, 16 September 1991, http:/ / listserv.linguistlist.org/cgi-bin/wa?A2=ind9109c\&L=linguist\&P $=524$, accessed on 29 January 2008. 
Sweet, Henry. A new English grammar. Logical and historical. Part I. Oxford: Clarendon Press, 1898.

Temperley, David. "Ambiguity Avoidance in English Relative Clauses." Language 79 (2003): 464-84.

Trotta, Joe and Aimo Seppänen. "The Relative/Conjunction Interface: A Study of the Syntax of While/Whilst in Present-Day English." English Studies: A Journal of English Language and Literature 79:4 (1998): 349-66.

Wendt, Gustav. Syntax des heutigen English. Vol. I. Heidelberg: Carl Winter, 1911.

Zandvoort, R. W.. A Handbook of English Grammar. London/New York: Longman, 1957. 